\title{
Polyacrylonitrile Nanofiber Optimization as Precursor of Carbon Nanofibers for Supercapacitors
}

\author{
Yasin Altin*(i), Ayse Celik Bedeloglu \\ Department of Polymer Materials Engineering, Bursa Technical University, 16310 Bursa, TURKEY
}

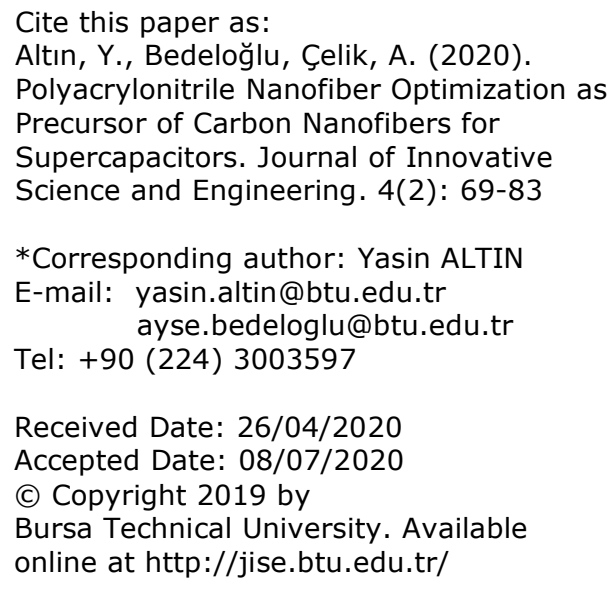

\section{(i) (9)}

The works published in Journal of Innovative Science and Engineering (JISE) are licensed under a Creative Commons Attribution-NonCommercial 4.0 International License.

\begin{abstract}
Polyacrylonitrile (PAN) nanofibers are one of the primary precursors in the production of carbon nanofibers. The nanofiber morphology is significantly affected by the process parameters such as polymer concentration, distance, applied voltage and feed rate during the production of PAN nanofibers obtained by the solution-based electrospinning method, and these parameters should be optimized properly. In this study, firstly PAN nanofiber production parameters were optimized, and then homogeneous and thin PAN nanofibers produced in optimum conditions were used as the precursor in the production of carbon nanofibers. PAN nanofibers with a diameter of $233 \mathrm{~nm}$ were obtained at 7.5\% PAN concentration in $\mathrm{N}, \mathrm{N}$-dimethylformamide (DMF), $28 \mathrm{kV}$ applied voltage, $17.5 \mathrm{~cm}$ nozzle to collector distance, $2 \mathrm{ml} / \mathrm{h}$ feed rate and $500 \mathrm{rpm}$ rotation speed of the aluminum drum. The carbon nanofiber diameters produced after the stabilization and carbonization processes were measured as 200 and $140 \mathrm{~nm}$, respectively. The morphological, chemical and thermal properties of the produced nanofibers were characterized by field emission scanning electron microscopy (FE-SEM), Fourier transform infrared (FT-IR), thermogravimetric analyzer (TGA). Carbon nanofibers, which are made from optimized electrospun PAN nanofibers, can be used to construct supercapacitors in future studies.
\end{abstract}

Keywords: Carbonization, Carbon Nanofiber, Electrospinning, PAN Nanofiber, Supercapacitor. 


\section{Introduction}

Carbon nanofibers are nanomaterials with nanoscale diameter that have been used in many application areas such as supercapacitors, rechargeable batteries, dye-sensitized solar cells, catalysis, sensors, and adsorption-desorption membranes as well as in the biomedical field. Therefore, they have attracted great attention in recent years [1-8]. Although carbon nanofibers can be produced via vapor growth or plasma-enhanced chemical vapor deposition techniques, the most common production is achieved through the stabilization and carbonization of polyacrylonitrile (PAN) nanofibers precursor due to the low cost, continuous, simple and easily controllable production process $[3,9,10]$. On the other hand, electrospinning is the most widely used method in nanofiber production. Electrospinning is generally divided into two types: (a) melt electrospinning and (b) solution-based electrospinning. The solution-based electrospinning method stands out because of the fact that nanofibers can be produced from various polymers such as polyacrylonitrile (PAN), poly (vinylidene fluoride) (PVDF), poly(vinyl alcohol) (PVA), polyamide 6,6, polycaprolactone (PCL), poly (vinylidene fluoride-co-hexafluoropropylene) (PVDF-co-HFP), thermoplastic polyurethane (TPU) and that the nanofiber properties can be controlled more easily [11-19]. The parameters affecting nanofiber morphology in the solution-based electrospinning method can be listed as temperature, humidity, solution viscosity (polymer concentration), the distance between nozzle and collector electrode, feed rate and the applied potential [20-22]. The determination of optimum process parameters is important to obtain nanofibers with desired properties.

This study aimed to investigate the influence of polymer concentration, distance, feed rate and applied voltage on the morphology of PAN nanofibers. The PAN nanofiber production was carried out using the production parameters determined by the production rate, continuity and nanofiber morphology. After the PAN nanofibers were stabilized in an air environment at $90{ }^{\circ} \mathrm{C}$ for 90 minutes, the stabilized nanofibers were successfully carbonized at $1000{ }^{\circ} \mathrm{C}$ for 3 hours in an argon atmosphere, and carbon nanofibers were successfully obtained. The current study also tried to investigate the chemical, thermal and morphological properties of the obtained PAN, stabilized PAN (St-PAN) and carbon nanofibers.

\section{Material and Methods}

\subsection{Materials}

Polyacrylonitrile (PAN) $\quad\left(\mathrm{M}_{\mathrm{w}}=150000 \mathrm{~g} / \mathrm{mole}\right)$ was obtained from $\mathrm{J} \& \mathrm{~K}$ Scientific (Shanghai, China), N,Ndimethylformamide (DMF, $\geq 99 \mathrm{wt} \%$ ) was purchased from Sigma-Aldrich and used as received without further purification.

\subsection{Optimization of PAN Nanofiber Production}

\subsubsection{Preparation of Polymer Solutions}

The required amount of PAN was added into DMF and stirred overnight at $80^{\circ} \mathrm{C}$. PAN solutions of $7.5 \%, 10 \%, 12.5 \%$, $15 \%$ by mass were used in the study. 


\subsubsection{Optimization of Electrospinning Parameters}

Inovenso Nanospinner 24 electrospinning device was used to produce nanofiber mats. Figure 1 illustrates the electrospinning setup. In this study, the effects of 4 different parameters on nanofiber production were investigated. For this purpose, nanofibers were produced using 4 different polymer concentrations $(7.5,10,12.5,15$ wt.\%), 4 different nozzle-to-collector distance $(12.5,15,17.5,20 \mathrm{~cm}), 4$ different feed rates $(1,1.5,2,3 \mathrm{ml} / \mathrm{h}), 3$ different applied voltages $(25,30,35 \mathrm{kV})$. The electrospinning conditions listed in Table 1 were used the produce nanofiber mats. According to the parameters applied here, the sample codes were named S1-S13, which are presented in Table 1 with electrospinning conditions.

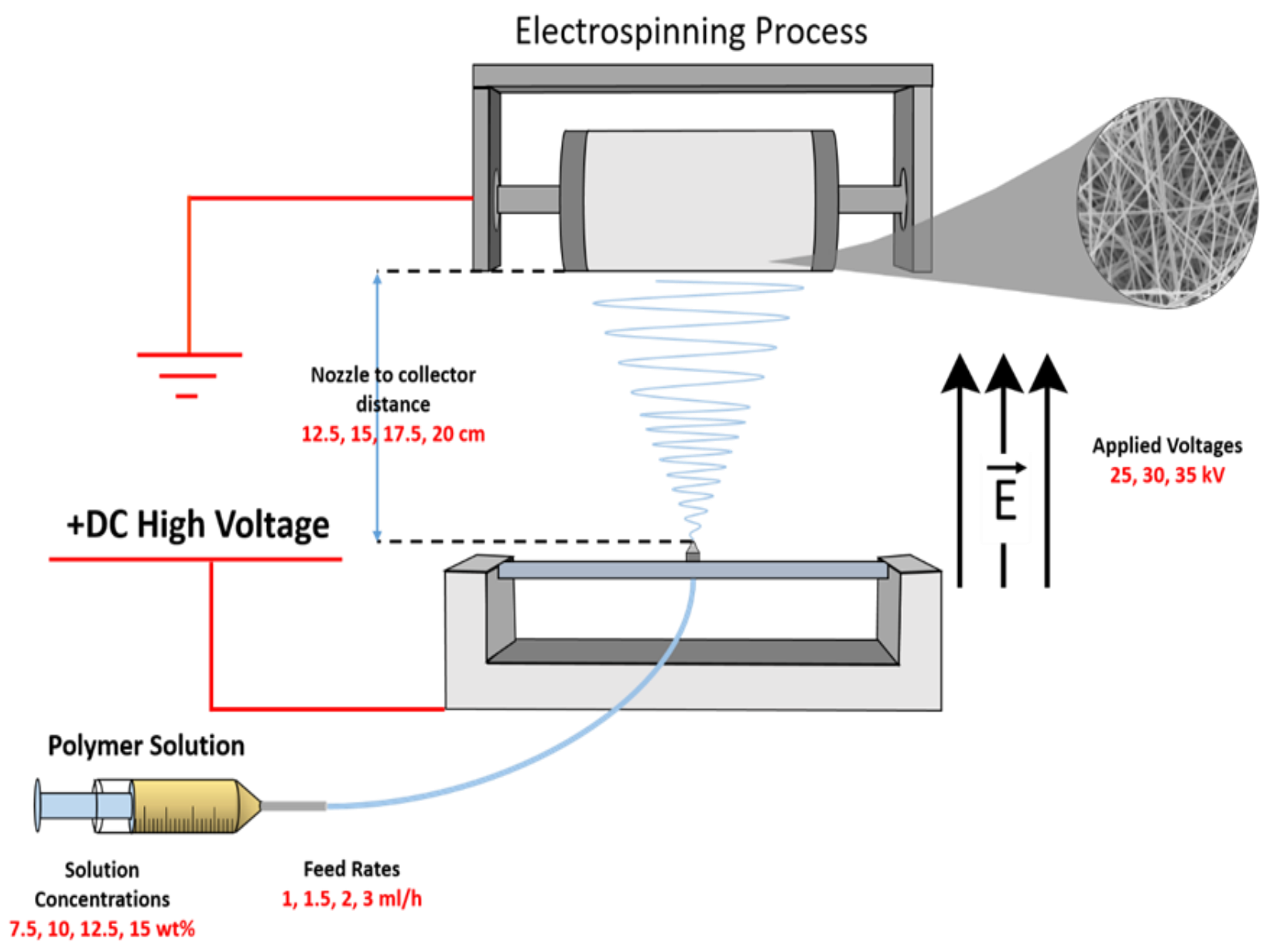

Figure 1. Schematic illustration of electrospinning process. 
Table 1. Electrospinning Parameters of PAN Nanofiber Production

\begin{tabular}{|c|c|c|c|c|c|}
\hline \multirow{6}{*}{ 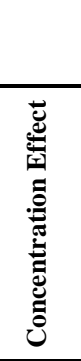 } & Sample & Variable Parameter & \multicolumn{3}{|c|}{ Constant Parameters } \\
\hline & & Concentration (wt.\%) & Distance (cm) & Feed Rate (ml/h) & Voltage (V) \\
\hline & S1 & $7.5 \%$ & $20 \mathrm{~cm}$ & $2 \mathrm{ml} / \mathrm{h}$ & $30 \mathrm{kV}$ \\
\hline & $\mathrm{S} 2$ & $10 \%$ & $20 \mathrm{~cm}$ & $2 \mathrm{ml} / \mathrm{h}$ & $30 \mathrm{kV}$ \\
\hline & S3 & $12.5 \%$ & $20 \mathrm{~cm}$ & $2 \mathrm{ml} / \mathrm{h}$ & $30 \mathrm{kV}$ \\
\hline & S4 & $15 \%$ & $20 \mathrm{~cm}$ & $2 \mathrm{ml} / \mathrm{h}$ & $30 \mathrm{kV}$ \\
\hline \multirow{5}{*}{ 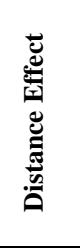 } & & Distance (cm) & Concentration (wt.\%) & Feed Rate (ml/h) & Voltage (V) \\
\hline & S5 & $12.5 \mathrm{~cm}$ & $12.5 \%$ & $2 \mathrm{ml} / \mathrm{h}$ & $30 \mathrm{kV}$ \\
\hline & S6 & $15 \mathrm{~cm}$ & $12.5 \%$ & $2 \mathrm{ml} / \mathrm{h}$ & $30 \mathrm{kV}$ \\
\hline & S7 & $17.5 \mathrm{~cm}$ & $12.5 \%$ & $2 \mathrm{ml} / \mathrm{h}$ & $30 \mathrm{kV}$ \\
\hline & S3 & $20 \mathrm{~cm}$ & $12.5 \%$ & $2 \mathrm{ml} / \mathrm{h}$ & $30 \mathrm{kV}$ \\
\hline \multirow{5}{*}{ 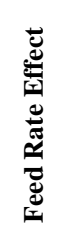 } & & Feed Rate $(\mathrm{ml} / \mathrm{h})$ & Distance (cm) & Concentration (wt.\%) & Voltage (V) \\
\hline & S8 & $1 \mathrm{ml} / \mathrm{h}$ & $15 \mathrm{~cm}$ & $12.5 \%$ & $30 \mathrm{kV}$ \\
\hline & S9 & $1.5 \mathrm{ml} / \mathrm{h}$ & $15 \mathrm{~cm}$ & $12.5 \%$ & $30 \mathrm{kV}$ \\
\hline & S6 & $2 \mathrm{ml} / \mathrm{h}$ & $15 \mathrm{~cm}$ & $12.5 \%$ & $30 \mathrm{kV}$ \\
\hline & $\mathrm{S} 10$ & $3 \mathrm{ml} / \mathrm{h}$ & $15 \mathrm{~cm}$ & $12.5 \%$ & $30 \mathrm{kV}$ \\
\hline \multirow{4}{*}{ 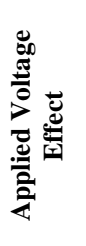 } & & Voltage (V) & Distance (cm) & Concentration (wt.\%) & $\begin{array}{c}\begin{array}{c}\text { Feed Rate } \\
(\mathrm{ml} / \mathrm{h})\end{array} \\
\end{array}$ \\
\hline & S11 & $25 \mathrm{kV}$ & $20 \mathrm{~cm}$ & $15 \%$ & $2 \mathrm{ml} / \mathrm{h}$ \\
\hline & S4 & $30 \mathrm{kV}$ & $20 \mathrm{~cm}$ & $15 \%$ & $2 \mathrm{ml} / \mathrm{h}$ \\
\hline & $\mathrm{S} 12$ & $35 \mathrm{kV}$ & $20 \mathrm{~cm}$ & $15 \%$ & $2 \mathrm{ml} / \mathrm{h}$ \\
\hline 咅 总 & $\mathrm{S} 13$ & $28 \mathrm{kV}$ & $17.5 \mathrm{~cm}$ & $7.5 \%$ & $2 \mathrm{ml} / \mathrm{h}$ \\
\hline
\end{tabular}

\subsection{Production of Carbon Nanofibers}

Among the conditions specified above, 7.5 wt.\% PAN in DMF, $28 \mathrm{kV}$ applied voltage, $17.5 \mathrm{~cm}$ nozzle-to-collector distance and $2 \mathrm{ml} / \mathrm{h}$ feed rate were determined as optimum electrospinning conditions, and PAN nanofibers mats were produced. For the stabilization of PAN nanofibers, it was heated up to $300{ }^{\circ} \mathrm{C}$ with a heating rate of $2{ }^{\circ} \mathrm{C} / \mathrm{min}$ and kept at $300{ }^{\circ} \mathrm{C}$ for $90 \mathrm{~min}$ in the air atmosphere. The stabilized PAN nanofibers were carbonized by gradual heating in the tube furnace in an argon atmosphere. First, it was heated up to $280^{\circ} \mathrm{C}$ with a heating rate of $10^{\circ} \mathrm{C} / \mathrm{min}$ and waited for 1 hour, then it was heated up to $1000{ }^{\circ} \mathrm{C}$ with a heating rate of $5^{\circ} \mathrm{C} / \mathrm{min}$ and kept for 3 hours at $1000{ }^{\circ} \mathrm{C}$. At the end of the process, carbon nanofibers were successfully obtained. Figure 2 demonstrates the time-temperature profile during stabilization and carbonization. 

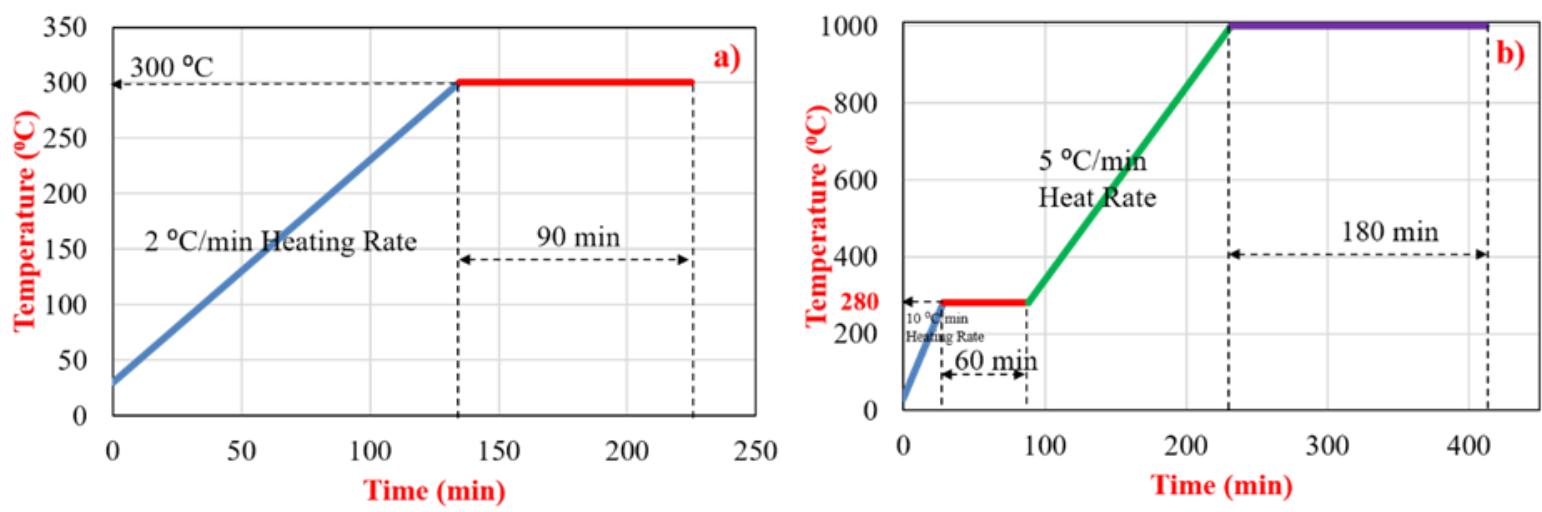

Figure 2. Time-temperature profile during a) Stabilization, b) Carbonization processes.

\subsection{Characterization}

The chemical structure of nanofibers was characterized by Fourier transform infrared spectroscopy (FT-IR) in the range of 4000-400 $\mathrm{cm}^{-1}$ with a $4 \mathrm{~cm}^{-1}$ spectral resolution on a Thermo Scientific Nicolet i550 model FTIR spectrometer with Smart Orbit-Diamond model ATR on transmittance mode. The morphology of nanofibers was investigated via field emission scanning electron microscope (FE-SEM) (Zeiss-Gemini 300) with field emission electron gun set at $20 \mathrm{kV}$ and $10 \mathrm{~mm}$ working distance. The diameter of nanofiber was calculated via ImageJ 1.51j8 software based on SEM images. Thermogravimetric analysis (TGA) was carried out in the temperature range from 30 to $900{ }^{\circ} \mathrm{C}$ under a nitrogen atmosphere at a rate of $10^{\circ} \mathrm{C} \mathrm{min}^{-1}$ on a Perkin Elmer-STA6000 (Perkin Elmer, Waltham, MA, USA) thermogravimetric analyzer.

\section{Results and Discussion}

One of the most important parameters affecting the nanofiber morphology is the viscosity of the polymer solution. The solution viscosity is also directly proportional to the polymer concentration and the molecular weight of the polymer. The studies in the relevant literature reveals that uniform nanofibres cannot be obtained and beads are observed as a result of the solution viscosity below a certain value [23-27]. Moreover, too high viscosity adversely affects fiber formation and increases nanofiber diameters.

Figure 3 shows the SEM images of PAN nanofibers obtained from PAN solutions at different polymer concentrations (7.5 wt \%, $10 \mathrm{wt} \%, 12.5 \mathrm{wt} \%, 15 \mathrm{wt} \%$ ). While S1, S2 and S3 had more homogeneous and uniform nanofiber surfaces, it was seen in the S4 sample that fiber thicknesses increase, and joints occur at the intersection points of nanofibers. The average diameters of nanofibers are shown in Figure 5-a. The diameters of S1, S2, S3 and S4 samples were measured as $275 \pm 57,334 \pm 67,575 \pm 101,1925 \pm 401 \mathrm{~nm}$, respectively. The increase in polymer concentration in the solution appears to enhance viscosity; consequently, this has a huge effect on the nanofiber diameter. 

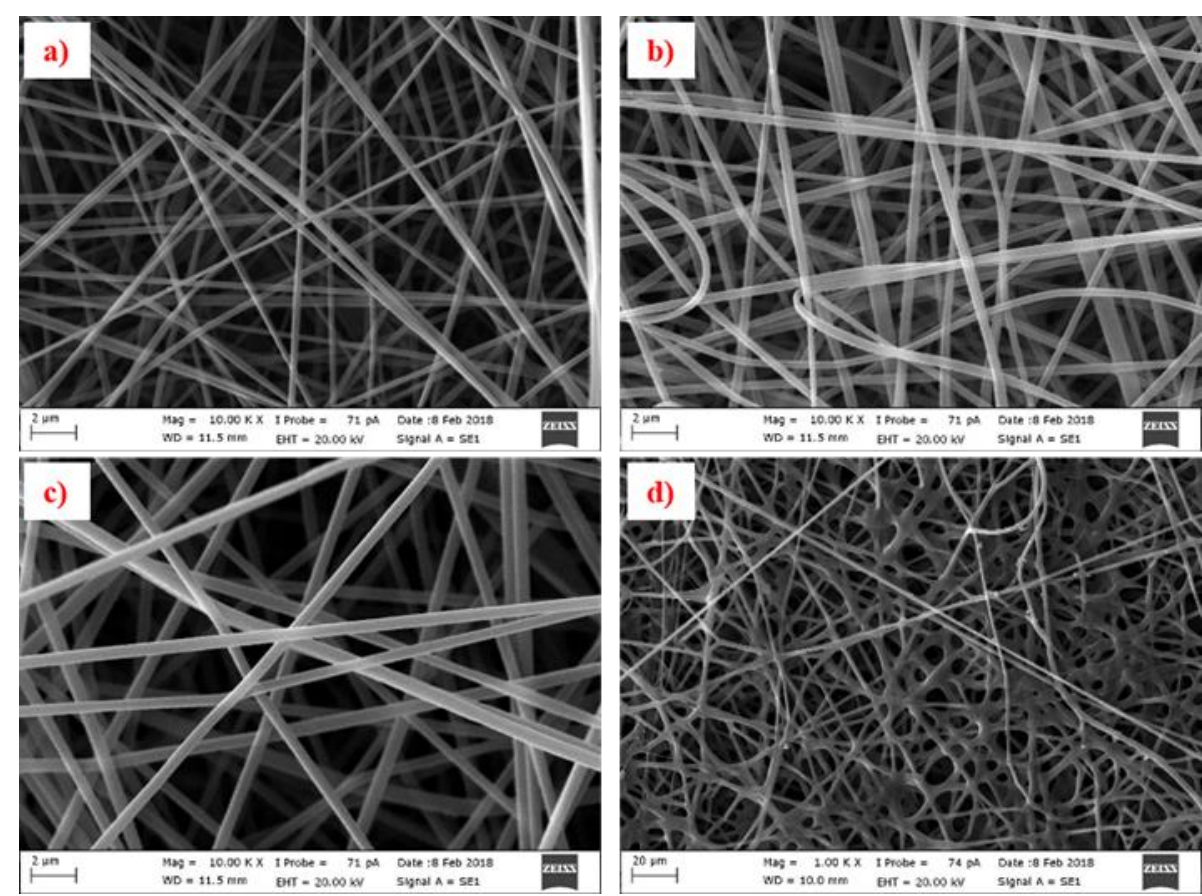

Figure 3. SEM image of nanofibers produced at different polymer concentrations a) S1 (10k x), b) S2 (10k x), c) S3 (10k x), d) S4 (1k x).

Figure 4 demonstrates the SEM images of nanofibers produced at the different nozzle to collector distance. It was observed that all nanofibers obtained are smooth and homogeneous. Figure 5-b displays the average diameter of nanofibers produced at the different distances. S5, S6, S7, S3 diameters were measured as $549 \pm 113,508 \pm 99,526 \pm 72$, $575 \pm 101 \mathrm{~nm}$, respectively.

Although some studies in the related literature mention that the increase in distance decreases the diameter of the nanofiber, no direct correlation has been observed in our study [28,29]. Considering the standard deviations, a decreasing trend of $12.5 \mathrm{~cm}$ to $17.5 \mathrm{~cm}$ appears, but the nanofibers produced at a distance of $20 \mathrm{~cm}$ are the thickest nanofibers. It is thought that the effect caused by parameters such as temperature and humidity that we cannot control due to being produced at different times may have suppressed the effect caused by nozzle to collector distance. 

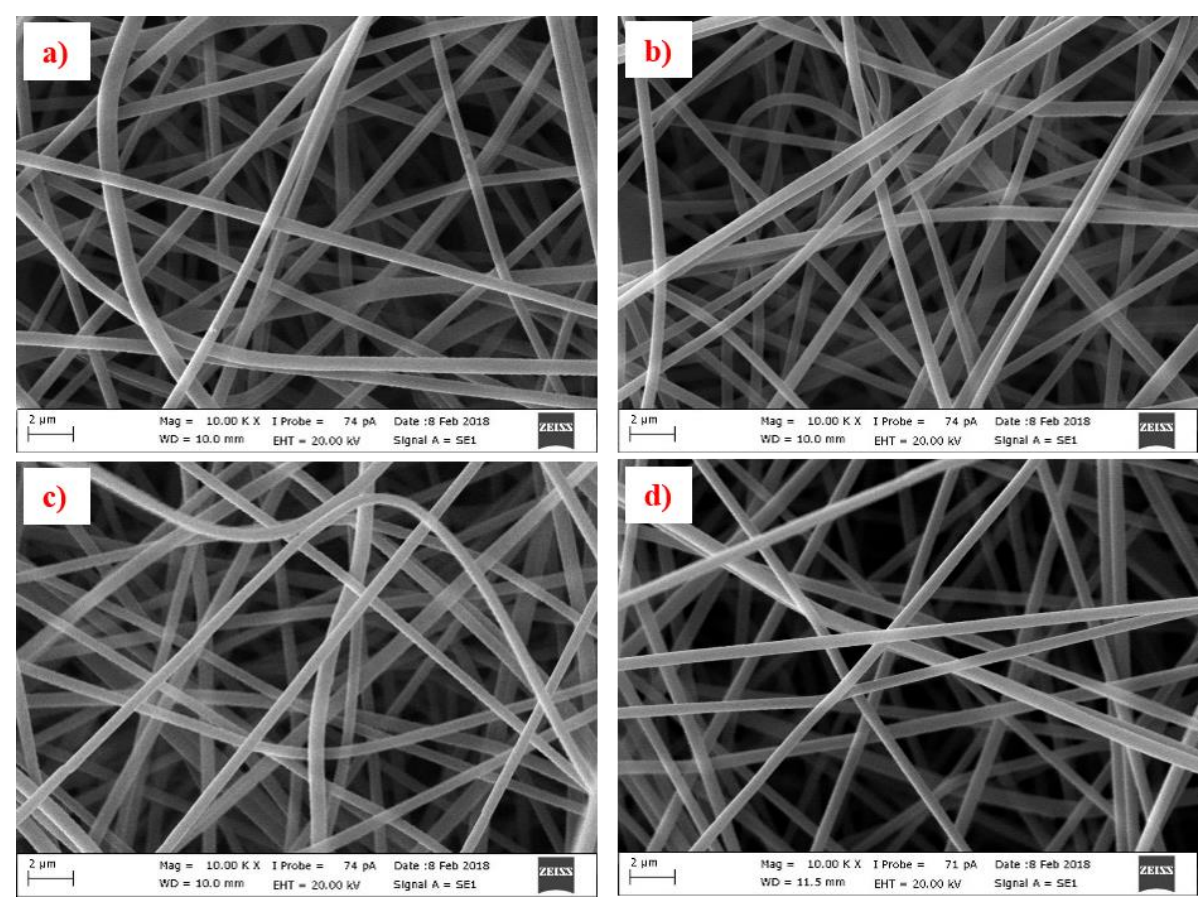

Figure 4. SEM image of nanofibers produced at different nozzle-to-collector distance a) S5 (10k x), b) S6 (10k x), c) S7 (10k x),

d) S3 (10k x).
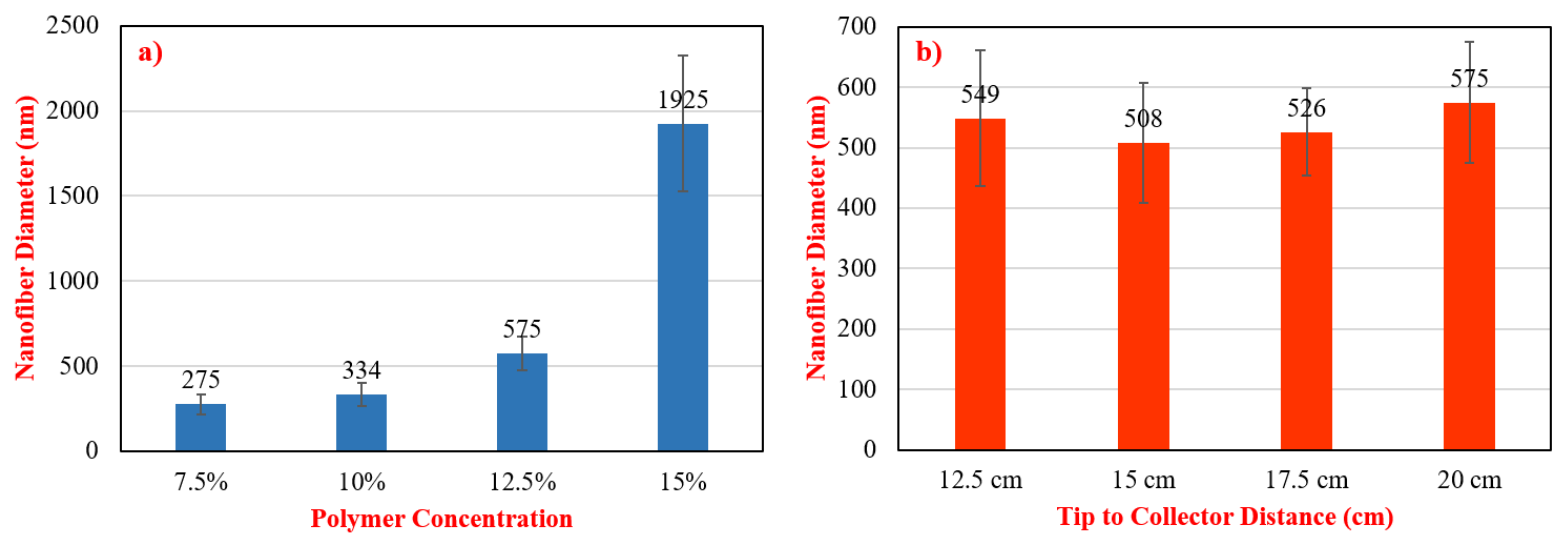

Figure 5. a) Polymer concentration and b) Nozzle to collector distance effect on NF diameter.

Figure 6 illustrates the SEM images of nanofibers at different feed rates while the nanofiber diameters are plotted in Figure 8-a. Nanofiber diameters were calculated as $560 \pm 151,587 \pm 153,508 \pm 99,496 \pm 99 \mathrm{~nm}$, respectively. Most studies in the relevant literature suggest that the increase in feed rate increases the nanofiber diameter [30-33]. However, based on our experience on nanofiber, we can say that this effect is not seen in every feed rate increase. This increase is directly related to the nozzle diameter and the device configuration. No significant relationship has been observed in the above mentioned feed rate differences with the device we use. It is possible to observe this diameter increase in much higher feed rate differences. On the other hand, some studies state that the increase in feed rate decreases the nanofiber diameter [21]. 

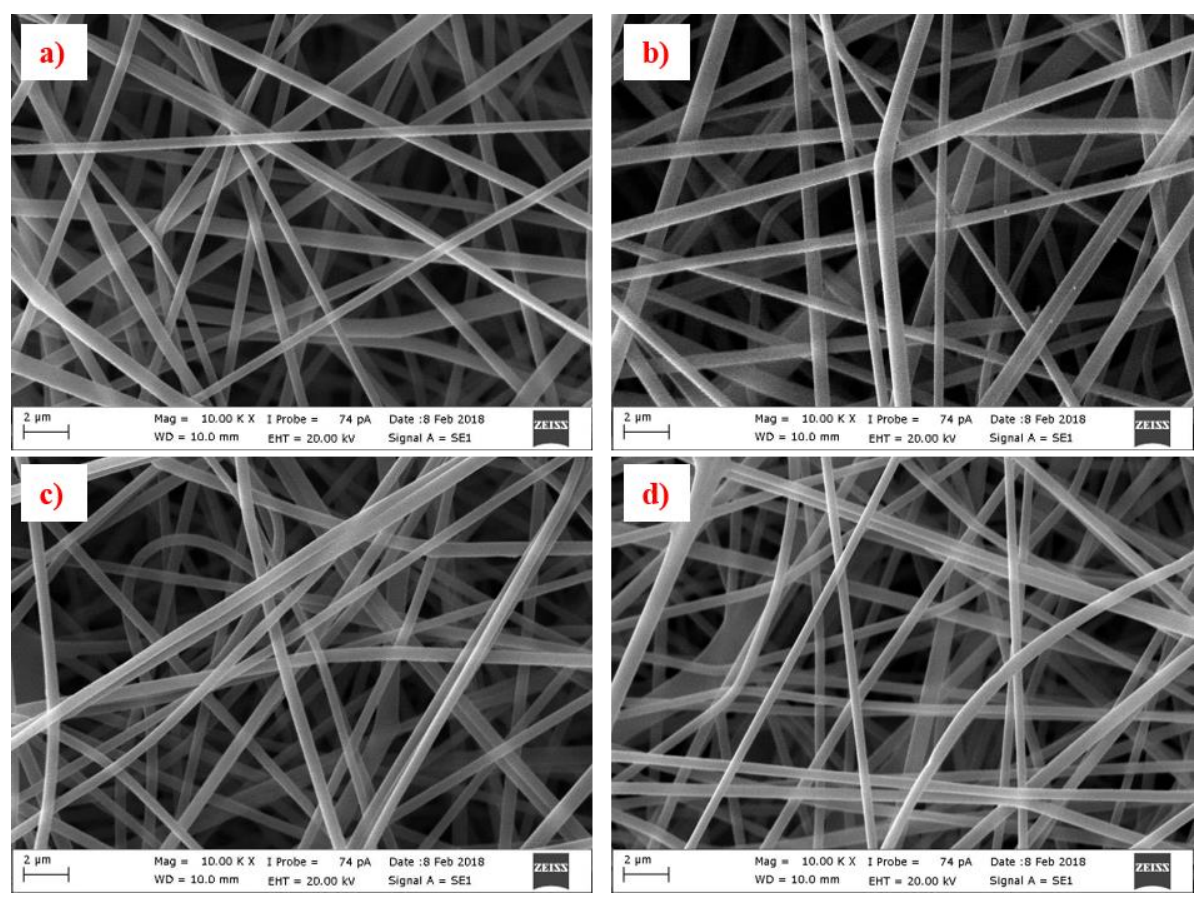

Figure 6. SEM image of nanofibers produced at different feed rates a) S8 (10k x), b) S9 (10k x), c) S6 (10k x), d) S10 (10k x).

Another important parameter of the electrospinning process is the applied voltage. It is mentioned in the literature that the applied voltage affects the initial droplet formation, feed rate and viscosity [34]. The electric field applied to the polymer droplet overcomes the surface tension of the droplet and creates a jet [35]. Nanofiber morphology can be manipulated by controlling the applied voltage. Increasing the applied voltage generally causes the nanofiber diameter to decrease [20,34,36,37]. However, when the critical voltage value is exceeded, an increase in fiber diameter can be seen due to the decrease in flight time. In addition, increasing the applied voltage causes multiple jet formation during production $[38,39]$.

Figure 7 shows the SEM images of nanofibers produced at different applied voltage values. At low voltage values, nanofibers appeared to stick together and move away from the fiber appearance. It was seen that more uniform and homogeneous nanofibers are obtained with an increase in voltage. Also in Figure 8-b, the diameter values of S11, S4 and S12 were measured as $1937 \pm 548,1925 \pm 401$ and $1917 \pm 339 \mathrm{~nm}$, respectively. As a result, it was seen that thinner and neat nanofibers are obtained by increasing the voltage. 

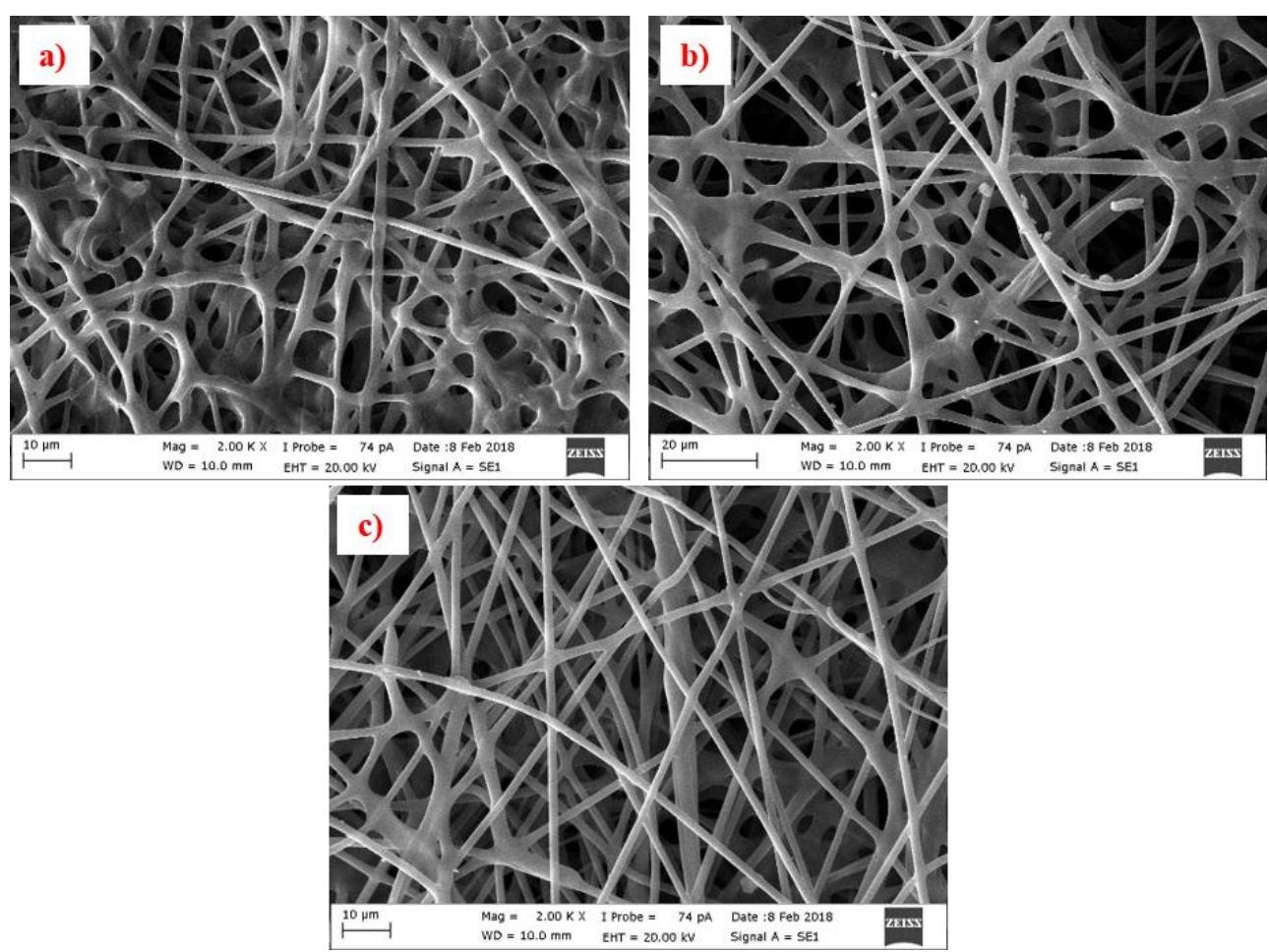

Figure 7. SEM image of nanofibers produced at different applied voltages a) S11 (2k x), b) S4 (2k x), c) S12 (2k x).
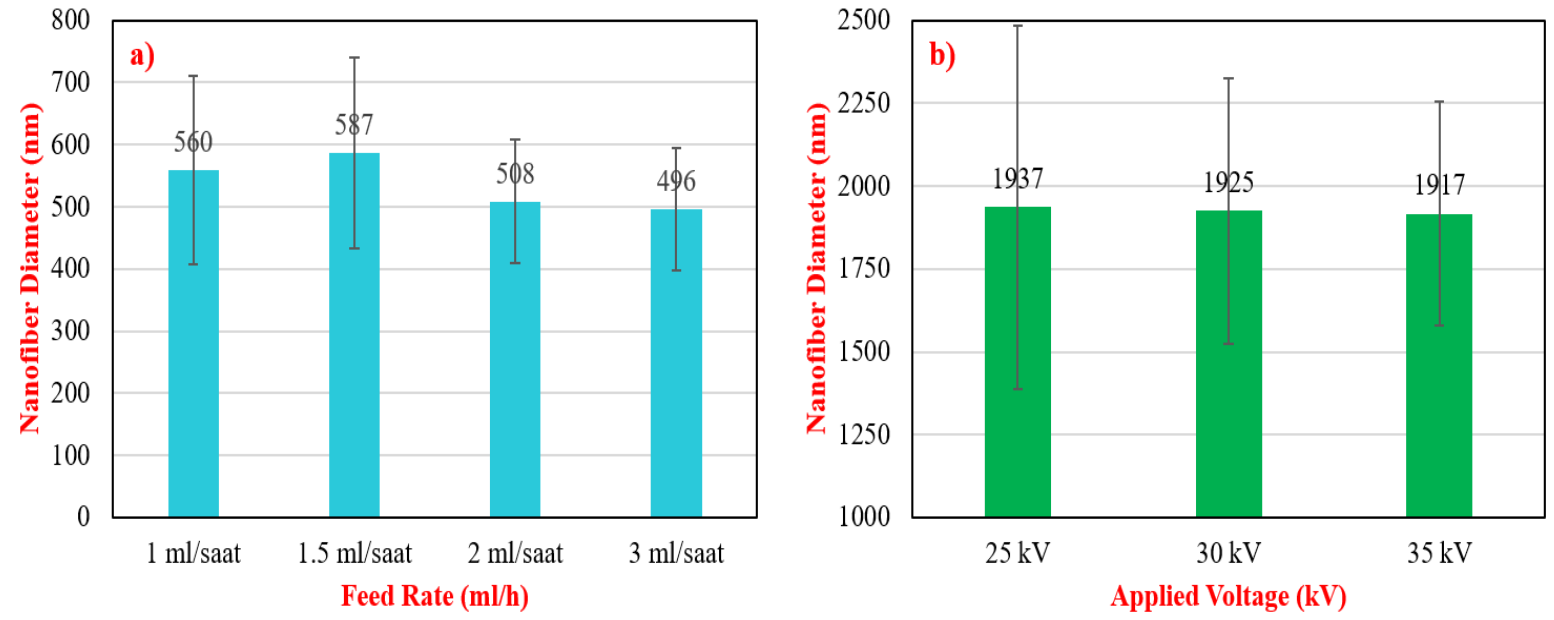

Figure 8. a) Feed rate b) Applied voltage effect on NF diameters.

Optimum parameters were determined as $7.5 \mathrm{wt} \%$ PAN concentration, $28 \mathrm{kV}$ applied voltage, $2 \mathrm{ml} /$ hour feed rate and $17.5 \mathrm{~cm}$ nozzle to collector distance based on the studies above mentioned considering production speed and production continuity. PAN nanofibers prepared at these parameters were produced, and then they were stabilized and carbonized. Figure 9 displays PAN nanofiber, stabilized PAN nanofiber and carbon nanofiber. 


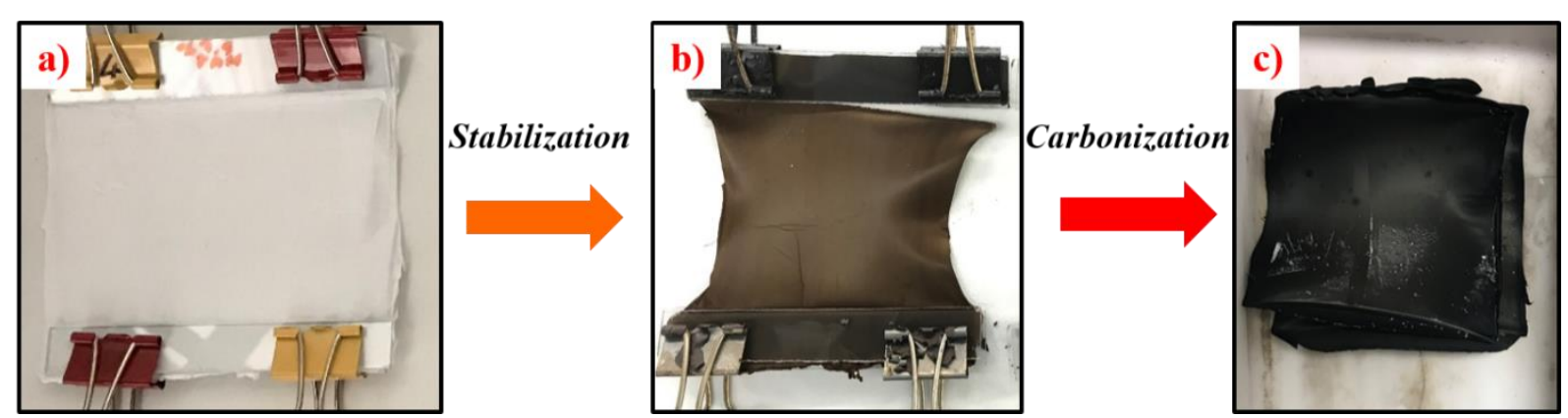

Figure 9. a) PAN NF (S13), b) Stabilized PAN NF, c) Carbon NF.

Figure 10 shows the average fiber diameters of PAN NF, Stb-PAN NF and carbon nanofibers, and Figure 11 displays SEM images of the samples. The average diameters of PAN NF were measured as $233 \pm 32 \mathrm{~nm}$, it dropped to $209 \pm 16 \mathrm{~nm}$ after the stabilization process. After carbonization, the diameter of carbon nanofibers was calculated as $140 \pm 17 \mathrm{~nm}$. As seen in Figure 11-c, homogeneous and thin carbon nanofibers were successfully obtained.

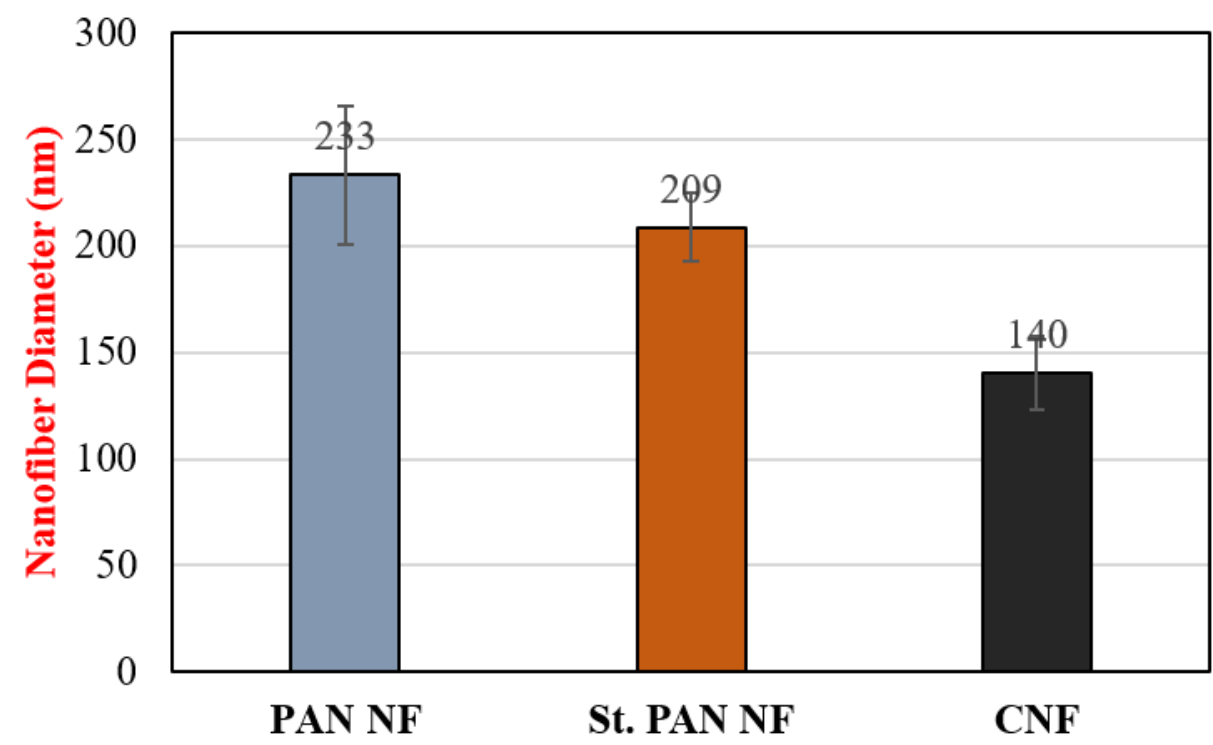

Figure 10. Diameter of PAN nanofiber, stabilized PAN nanofiber and carbon nanofiber.
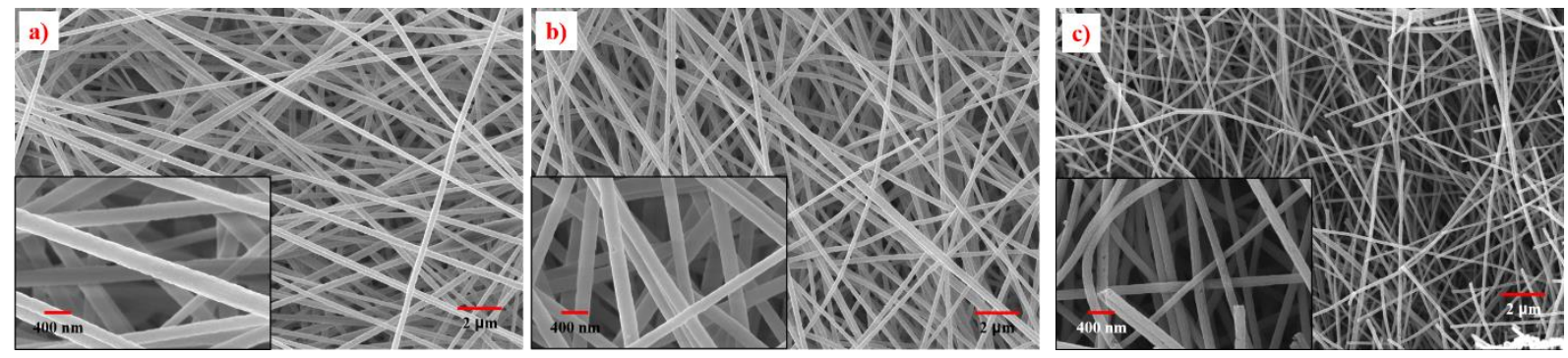

Figure 11. SEM images of a) PAN nanofiber, b) stabilized PAN nanofiber and c) carbon nanofiber.

Figure 12 illustrates the FT-IR spectra of PAN nanofiber, St-PAN nanofiber and carbon nanofiber. The characteristic absorption band of PAN nanofiber due to $-\mathrm{C} \equiv \mathrm{N}$ stretching can be seen in $2242 \mathrm{~cm}^{-1}$. Vibration of aliphatic $\mathrm{CH}$ groups $\left(\mathrm{CH}, \mathrm{CH}_{2}\right.$, and $\left.\mathrm{CH}_{3}\right)$ give peaks at $2939 \mathrm{~cm}^{-1}, 1453 \mathrm{~cm}^{-1}, 1357 \mathrm{~cm}^{-1}$, and $1251 \mathrm{~cm}^{-1}[40,41]$. 
During stabilization, $\mathrm{C} \equiv \mathrm{N}$ bonds in the PAN structure were broken and $\mathrm{C}=\mathrm{N}$ bonds were formed. This caused the intensity of $\mathrm{C} \equiv \mathrm{N}$ peaks seen at $2242 \mathrm{~cm}^{-1}$ to decrease and shift to $2230 \mathrm{~cm}^{-1}$. In addition, new peaks were formed as a result of the overlapping of the vibration peaks at different frequencies of functional groups such as $\mathrm{C}=\mathrm{C}, \mathrm{C}=\mathrm{N}, \mathrm{C}=\mathrm{O}$, and $\mathrm{N}-\mathrm{H}$ between $1760-980 \mathrm{~cm}^{-1}$ [42-44]. The peak was observed at $803 \mathrm{~cm}^{-1}$ due to the vibration of aromatic C-H bonds formed due to oxidative dehydrogenation in the presence of oxygen $[44,45]$. Within the scope of the studies in the relevant literature, the stabilization process of PAN was carried out in the range of $210-300{ }^{\circ} \mathrm{C}[17,42-44,46,47]$. As the stabilization temperature increased, the oxidation rate increased. For this reason, $300{ }^{\circ} \mathrm{C}$ was chosen as the stabilization temperature in our study. It was observed that most of the functional group peaks disappeared after the intense carbonization process carried out at $1000{ }^{\circ} \mathrm{C}$. These results indicated that the stabilization and carbonization processes were successfully performed.

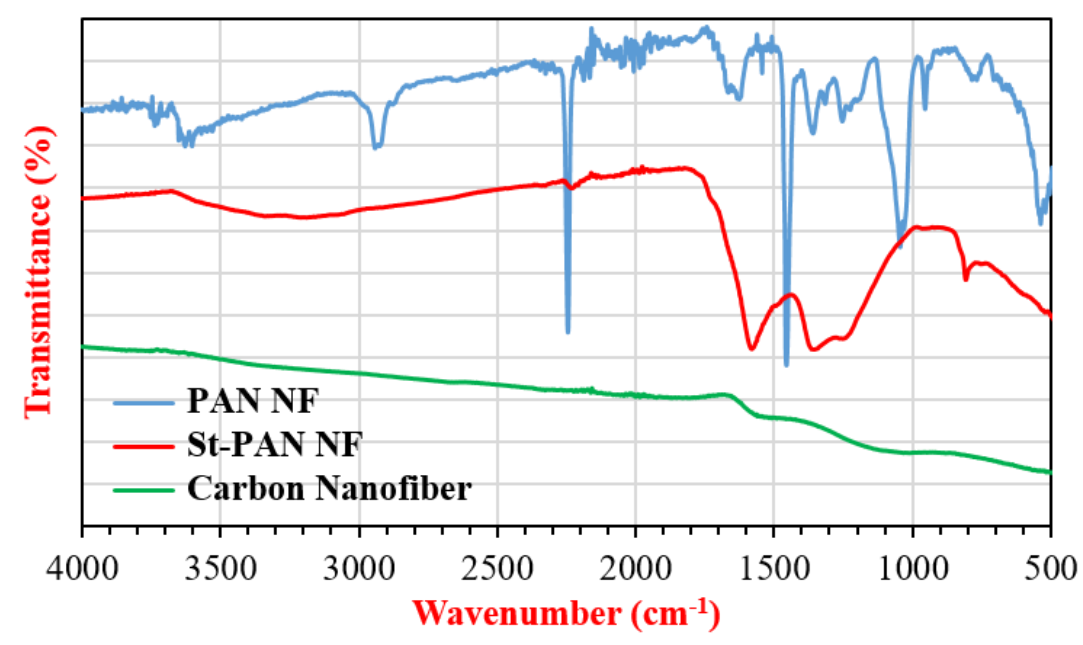

Figure 12. FT-IR spectrum of PAN NF, St-PAN NF, Carbon NF.

Figure 13 demonstrates TGA thermogram of PAN NF and St-PAN NF. PAN NF primarily lost its moisture at around $100{ }^{\circ} \mathrm{C}$. Afterwards, it was decomposed between $300-500{ }^{\circ} \mathrm{C}$ and left $29 \%$ residue around $900{ }^{\circ} \mathrm{C}$. During this degradation, random chain scission, cyclization, dehydrogenation, and cross-linking took place [48]. On the other hand, St-PAN NF sample started to carbonize around $300{ }^{\circ} \mathrm{C}$ after removing the moisture up to $100{ }^{\circ} \mathrm{C}$ [17]. The stabilization of PAN nanofiber increased carbon yield at the end of the carbonization process.

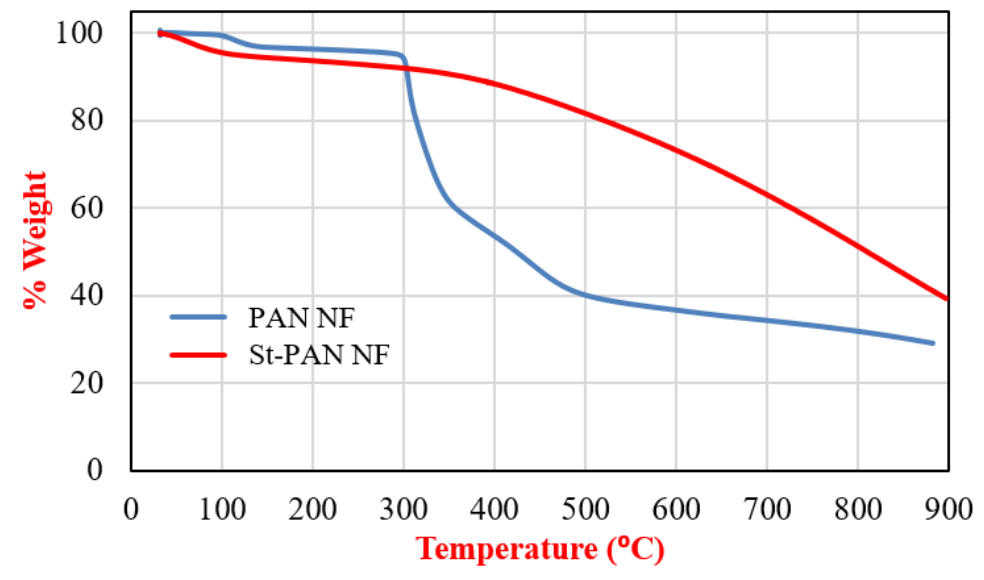

Figure 13. TGA thermogram of PAN NF and St-PAN NF. 


\section{Conclusion}

In this study, PAN polymer was electrospun on an aluminum drum rotating at $500 \mathrm{rpm}$ at different polymer concentrations, applied voltages, feed rates, and nozzle to collector distances, and it aimed to investigate the effect of these parameters on PAN nanofiber morphology. In the light of study results, it was observed that the most important parameter affecting polymer morphology was polymer concentration, and the nanofiber diameter decreased with decreasing polymer concentration. Although the studies in the related literature stated that increasing the distance decreases the nanofiber diameter, no correlative relationship was observed between the distances examined in this study. In addition, unlike the most studies in the literature, a decrease in nanofiber diameter was observed with increasing feed rates generally. It was perceived that more smooth and thin nanofibers were obtained with the increase of applied voltage. Taking the parameters tested into account, polymer solution concentration, the distance between nozzle and collector electrode, feed rate, and the applied potential were determined as $7.5 \mathrm{w} \%, 17.5 \mathrm{~cm}, 2 \mathrm{ml} / \mathrm{h}$, and $28 \mathrm{kV}$, respectively; and then PAN nanofibers were produced. The diameters of PAN nanofibers produced under these conditions were measured as $233 \pm 32 \mathrm{~nm}$ and used as a precursor for carbon nanofiber production. The PAN nanofiber precursor was first stabilized in the air atmosphere at $280{ }^{\circ} \mathrm{C}$, and then it was carbonized in argon atmosphere at $1000^{\circ} \mathrm{C}$ to obtain carbon nanofibers. After stabilization and carbonization, nanofiber diameters were calculated as $209 \pm 16 \mathrm{~nm}$ and $140 \pm 17 \mathrm{~nm}$, respectively. FT-IR analysis confirmed that the stabilization and carbonization processes have been successfully performed. On the other hand, TGA results showed that the thermal stability of stabilized PAN nanofibers is higher than that of PAN nanofibers. This optimization study is of utmost importance since it produces carbon nanofiber material under the optimum conditions and it provides guidance for future supercapacitor applications.

\section{Acknowledgments}

This work was supported as a PhD research project by Bursa Technical University Scientific Research Project (BAP) Unit, Project Number: 172D32. We owe special thanks to Prof. Dr. Ali Demir and ITU-TEMAG lab for their help on tube furnace usage.

\section{References}

[1] Jadhav, S.A., S.B. Dhavale, A.H. Patil and P.S. Patil, (2019). Brief overview of electrospun polyacrylonitrile carbon nanofibers: Preparation process with applications and recent trends. Material Design \& Processing Communications, 1(5): https://doi.org/10.1002/mdp2.83

[2] Gu, S.Y., J. Ren and Q.L. Wu, (2005). Preparation and structures of electrospun PAN nanofibers as a precursor of carbon nanofibers. Synthetic Metals, 155(1): 157-161

[3] Inagaki, M., Y. Yang and F. Kang, (2012). Carbon nanofibers prepared via electrospinning. Advanced Materials, 24(19): 2547-2566

[4] Kim, C. and K.S. Yang, (2003). Electrochemical properties of carbon nanofiber web as an electrode for supercapacitor prepared by electrospinning. Applied Physics Letters, 83(6): 1216-1218

[5] Kim, C., K.S. Yang, M. Kojima, K. Yoshida, Y.J. Kim, Y.A. Kim and M. Endo, (2006). Fabrication of 
electrospinning-derived carbon nanofiber webs for the anode material of lithium-ion secondary batteries. Advanced Functional Materials, 16(18): 2393-2397

[6] Wang, Z., S. Wu, J. Wang, A. Yu and G. Wei, (2019). Carbon nanofiber-based functional nanomaterials for sensor applications. Nanomaterials, 9(7): 1045

[7] Lu, W., T. He, B. Xu, X. He, H. Adidharma, M. Radosz, K. Gasem and M. Fan, (2017). Progress in catalytic synthesis of advanced carbon nanofibers. Journal of Materials Chemistry A, 5(27): 13863-13881

[8] Thamer, B.M., H. El-Hamshary, S.S. Al-Deyab and M.H. El-Newehy, (2019). Functionalized electrospun carbon nanofibers for removal of cationic dye. Arabian Journal of Chemistry, 12(6): 747-759

[9] Ismar, E. and A.S. Sarac, (2016). Synthesis and characterization of poly (acrylonitrile-co-acrylic acid) as precursor of carbon nanofibers. Polymers for Advanced Technologies, 27(10): 1383-1388

[10] Ma, C., X. Wang, Y. Ma, J. Sheng, Y. Li, S. Li and J. Shi, (2015). Carbon nanofiber/graphene composite paper for flexible supercapacitors with high volumetric capacitance. Materials Letters, 145: 197-200

[11] Ünsal, Ö.F., Y. Altın and A. Çelik Bedeloğlu, Poly(vinylidene fluoride) nanofiber-based piezoelectric nanogenerators using reduced graphene oxide/polyaniline. Journal of Applied Polymer Science, 0(0): 48517

[12] Can, M.F., L. Avdan and A.C. Bedeloglu, (2015). Properties of biodegradable PVA/sepiolite-based nanocomposite fiber mats. Polymer Composites, 36(12): 2334-2342

[13] Bedeloglu, A.C. and Z.I. Cin, (2019). Functional sol-gel coated electrospun polyamide 6,6/ZnO composite nanofibers. Journal of Polymer Engineering, 39(8): 752-761

[14] Bhullar, S.K., D. Rana, H. Lekesiz, A.C. Bedeloglu, J. Ko, Y. Cho, Z. Aytac, T. Uyar, M. Jun and M. Ramalingam, (2017). Design and fabrication of auxetic PCL nanofiber membranes for biomedical applications. Materials Science and Engineering C, 81: 334-340

[15] Tas, M., H. Memon, F. Xu, I. Ahmed and X. Hou, (2020). Electrospun nanofibre membrane based transparent slippery liquid-infused porous surfaces with icephobic properties. Colloids and Surfaces A: Physicochemical and Engineering Aspects, 585: 124177

[16] Tas, M., F. Xu, I. Ahmed and X. Hou, (2020). One-step fabrication of superhydrophobic P(VDF-co-HFP) nanofibre membranes using electrospinning technique. Journal of Applied Polymer Science, 137(24): 48817

[17] Wu, M., Q. Wang, K. Li, Y. Wu and H. Liu, (2012). Optimization of stabilization conditions for electrospun polyacrylonitrile nanofibers. Polymer Degradation and Stability, 97(8): 1511-1519

[18] Al-Hazeem, N.Z.A., (2018). Nanofibers and Electrospinning Method, In Nov. Nanomater. - Synth. Appl., George Kyzas, ed., InTechOpen, pp: 191-210

[19] Dasdemir, M., M. Topalbekiroglu and A. Demir, (2013). Electrospinning of thermoplastic polyurethane microfibers and nanofibers from polymer solution and melt. Journal of Applied Polymer Science, 127(3): 1901-1908

[20] Beachley, V. and X. Wen, (2009). Effect of electrospinning parameters on the nanofiber diameter and length. Materials Science and Engineering C, 29(3): 663-668

[21] Bakar, S.S.S., K.C. Fong, A. Eleyas and M.F.M. Nazeri, (2018). Effect of Voltage and Flow Rate Electrospinning Parameters on Polyacrylonitrile Electrospun Fibers, In IOP Conf. Ser. Mater. Sci. Eng., , p: 012076

[22] Homayoni, H., S.A.H. Ravandi and M. Valizadeh, (2009). Electrospinning of chitosan nanofibers: Processing optimization. Carbohydrate Polymers, 77(3): 656-661

[23] Huan, S., G. Liu, G. Han, W. Cheng, Z. Fu, Q. Wu and Q. Wang, (2015). Effect of experimental parameters on morphological, mechanical and hydrophobic properties of electrospun polystyrene fibers. Materials, 8(5): $2718-2734$

[24] Ojha, S., (2017). Structure-property relationship of electrospun fibers, In Electrospun Nanofibers, Mehdi Afshari, ed., Woodhead Publishing, pp: 239-253 
[25] Salas, C., (2017). Solution electrospinning of nanofibers, In Electrospun Nanofibers, M. Afshari, ed., Woodhead Publishing, pp: 73-108

[26] McKee, M.G., G.L. Wilkes, R.H. Colby and T.E. Long, (2004). Correlations of Solution Rheology with Electrospun Fiber Formation of Linear and Branched Polyesters. Macromolecules, 37(5): 1760-1767

[27] Korycka, P., A. Mirek, K. Kramek-Romanowska, M. Grzeczkowicz and D. Lewinska, (2018). Effect of electrospinning process variables on the size of polymer fibers and bead-on-string structures established with a 23 factorial design. Beilstein Journal of Nanotechnology, 9(1): 2466-2478

[28] Yuan, X.Y., Y.Y. Zhang, C. Dong and J. Sheng, (2004). Morphology of ultrafine polysulfone fibers prepared by electrospinning. Polymer International, 53(11): 1704-1710

[29] İkiz, Y., (2009). Elektro Çekim Yöntemi İşlem Parametrelerinin PVA Nanolif Morfolojisine Etkileri Effect of Process Parameters on Morphology of Electrospun PVA Nanofibers. Pamukkale University Journal of Engineering Sciences, 15(3): 363-369

[30] Tang, X.P., N. Si, L. Xu and H.Y. Liu, (2014). Effect of flow rate on diameter of electrospun nanoporous fibers. Thermal Science, 18(5): 1447-1449

[31] Megelski, S., J.S. Stephens, D. Bruce Chase and J.F. Rabolt, (2002). Micro- and nanostructured surface morphology on electrospun polymer fibers. Macromolecules, 35(22): 8456-8466

[32] Mujica-Garcia, A., I. Navarro-Baena, J.M. Kenny and L. Peponi, (2014). Influence of the processing parameters on the electrospinning of biopolymeric fibers. Journal of Renewable Materials, 2(1): 23-34

[33] Chen, Y.P., H.Y. Liu, Y.W. Liu, T.Y. Lee and S.J. Liu, (2019). Determination of electrospinning parameters' strength in Poly(D,L)-lactide-co-glycolide micro/nanofiber diameter tailoring. Journal of Nanomaterials, 2019:

[34] Khajavi, R. and M. Abbasipour, (2017). Controlling nanofiber morphology by the electrospinning process, In Electrospun Nanofibers, , pp: 109-123

[35] SalehHudin, H.S., E.N. Mohamad, W.N.L. Mahadi and A. Muhammad Afifi, (2018). Multiple-jet electrospinning methods for nanofiber processing: A review. Materials and Manufacturing Processes, 33(5): $479-498$

[36] Sener, A.G., A.S. Altay and F. Altay, (2011). Effect of voltage on morphology of electrospun nanofibers, In ELECO 2011 - 7th Int. Conf. Electr. Electron. Eng., , pp: 324-I-328

[37] Lee, J.S., K.H. Choi, H. Do Ghim, S.S. Kim, D.H. Chun, H.Y. Kim and W.S. Lyoo, (2004). Role of molecular weight of atactic poly(vinyl alcohol) (PVA) in the structure and properties of PVA nanofabric prepared by electrospinning. Journal of Applied Polymer Science, 93(4): 1338-1346

[38] Wu, Y.K., L. Wang, J. Fan, W. Shou, B.M. Zhou and Y. Liu, (2018). Multi-jet electrospinning with auxiliary electrode: The influence of solution properties. Polymers, 10(6): 572

[39] Liu, Z., K. Ju, Z. Wang, W. Li, H. Ke and J. He, (2019). Electrospun Jets Number and Nanofiber Morphology Effected by Voltage Value: Numerical Simulation and Experimental Verification. Nanoscale Research Letters, 14(1): 310

[40] Li, J., S. Su, L. Zhou, V. Kundrát, A.M. Abbot, F. Mushtaq, D. Ouyang, D. James, D. Roberts and H. Ye, (2013). Carbon nanowalls grown by microwave plasma enhanced chemical vapor deposition during the carbonization of polyacrylonitrile fibers. Journal of Applied Physics, 113(2): 024313

[41] Abeykoon, N.C., J.S. Bonso and J.P. Ferraris, (2015). Supercapacitor performance of carbon nanofiber electrodes derived from immiscible PAN/PMMA polymer blends. RSC Advances, 5(26): 19865-19873

[42] Xu, W., B. Xin and X. Yang, (2020). Carbonization of electrospun polyacrylonitrile (PAN)/cellulose nanofibril (CNF) hybrid membranes and its mechanism. Cellulose, 27: 3789-3804

[43] Duan, Q., B. Wang and H. Wang, (2012). Effects of stabilization temperature on structures and properties of polyacrylonitrile (PAN)-based stabilized electrospun nanofiber mats. Journal of Macromolecular Science, Part B: Physics, 51(12): 2428-2437 
[44] Gergin, I., E. Ismar and A.S. Sarac, (2017). Oxidative stabilization of polyacrylonitrile nanofibers and carbon nanofibers containing graphene oxide (GO): A spectroscopic and electrochemical study. Beilstein Journal of Nanotechnology, 8(1): 1616-1628

[45] Sabantina, L., R. Böttjer, D. Wehlage, T. Grothe, M. Klöcker, F.J. García-Mateos, J. Rodríguez-Mirasol, T. Cordero and A. Ehrmann, (2019). Morphological study of stabilization and carbonization of polyacrylonitrile/TiO2 nanofiber mats. Journal of Engineered Fibers and Fabrics, https://doi.org/10.1177/1558925019862242

[46] Sabantina, L., D. Wehlage, M. Klöcker, A. Mamun, T. Grothe, F.J. García-Mateos, J. Rodríguez-Mirasol, T. Cordero, K. Finsterbusch and A. Ehrmann, (2018). Stabilization of electrospun PAN/gelatin nanofiber mats for carbonization. Journal of Nanomaterials, Advanced Hybrid Functional Materials for Energy Applications Special Issue, https://doi.org/10.1155/2018/6131085

[47] Sabantina, L., M. Klöcker, M. Wortmann, J.R. Mirasol, T. Cordero, E. Moritzer, K. Finsterbusch and A. Ehrmann, (2019). Stabilization of polyacrylonitrile nanofiber mats obtained by needleless electrospinning using dimethyl sulfoxide as solvent. Journal of Industrial Textiles, DOI: 1528083718825315

[48] Aksoy, O.E., B. Ates and I. Cerkez, (2017). Antibacterial polyacrylonitrile nanofibers produced by alkaline hydrolysis and chlorination. Journal of Materials Science, 52: 10013-10022 